\title{
EL STEAMPUNK Y SU RESIGNIFICACIÓN DEL OBJETO DESDE LA ÓPTICA POSMODERNA
}

\section{STEAMPUNK AND ITS RESIGNIFICATION OF THE OBJECT FROM A POSTMODERNIST POINT OF VIEW}

\author{
José Antonio CALZÓN GARCÍA \\ Universidad de Cantabria \\ joseantoniocalzon@gmail.com
}

\begin{abstract}
Resumen: El artículo repasa, en primer lugar, las principales características del género steampunk, así como la evolución histórica, sus problemas de adscripción, sus implicaciones ideológicas o la naturaleza transversal de su discurso, entre otros aspectos. En segundo lugar, y una vez vista la naturaleza híbrida y posmoderna del género, estudia el desarrollo semiótico que el steampunk plantea a propósito de la resignificación de la relación sujeto-objeto desde una óptica postcapitalista y deconstructiva, poniendo para ello ejemplos concretos.
\end{abstract}

Palabras clave: Steampunk. Fetichismo. Ciencia ficción. Objeto. Retrofuturismo.

\begin{abstract}
This article will address, first of all, the main features of the steampunk genre, as well as its historical evolution, its problems of ascription, its ideological implications and the transverse nature of its discourse, among other aspects. Secondly, and once the hybrid and postmodern nature of this genre has been stablished, the article will analyse the semiotic development which steampunk sets out regarding the resignification of the subject-object relation from a postcapitalist and deconstructive point of view, providing specific examples.
\end{abstract}

Key Words: Steampunk. Fetishism. Science-fiction. Object. Retrofuturism. 


\section{EL STEAMPUNK. CARACTERÍSTICAS, HISTORIA E IMPACTO}

Autores, crítica y especialistas suelen estar más o menos de acuerdo en que el steampunk constituye un (sub)género narrativo de corte retrofuturista, en el que se plantea un universo ucrónico ambientado con frecuencia en Inglaterra a finales del siglo XIX o comienzos del XX, donde el protagonismo de la energía a vapor y de los dispositivos mecánicos se habría impuesto (Matangrano, 2016: 247-248) sobre el uso de los hidrocarburos y de la electrónica, deviniendo en un mundo alternativo (Pegoraro, 2013: 1852) al universo tal y como lo conocemos, y en el que realidad y fantasía se entremezclan: "As steampunk is a pastiche made of many elements, it is difficult to categorize something as quintessentially steampunk, and thus difficult to categorize something non-Victorian as steampunk unless incorporates elements that are absolutely recognizable" (Goh, 2009: 19). A esto se suman las relaciones con la literatura de corte ucrónico (Moreno, 2010: 263) o los diversos subgéneros que podemos encontrar, como el clockpunk, el dieselpunk (Fernández, 2011), el teslapunk y un largo etcétera que no hace sino complicar la labor del crítico a la hora de intentar categorizar, o definir, las distintas manifestaciones textuales.

Y así, siguiendo la estela de autores como Julio Verne o Herbert G. Wells ${ }^{1}$, Kevin W. Jeter, uno de los autores clásicos del género, acuñó en 1987 humorísticamente la expresión para referirse al tipo de producción que en esos momentos James Blaylock, Tim Powers o él mismo estaban llevando a cabo: "Personally, I think Victorian fantasies are going to be the next big thing, as long as we can come up with a fitting collective for Powers, Blaylock and myself. Something based on the appropriate technology of that era, like 'steampunks', perhaps" (Usher, 2011). En cualquier caso, ya algunas décadas antes ${ }^{2}$ autores como Michael Moorcock — responsable en gran medida de la fascinación steampunk por los dirigibles (Beard, 2014: XVII)—, con The Warlord of Air (1971); Harry Harrison, con A

\footnotetext{
${ }^{1}$ Sobre los orígenes decimonónicos del steampunk, véanse Nevins (2015: 9-12) o VanderMeer y Chambers (2011: 41).

${ }^{2}$ Entre las abundantes referencias para consultar los orígenes históricos del steampunk y su desarrollo, aconsejamos Nevins (2015: 9), Beard (2014: XVI y ss.), VanderMeer y Chambers (2011: 19-68) o Bowser y Croxall (2010: 12-15).
} 
Transatlantic Tunnel Hurrah (1972), o Ronald William Clark, con Queen Victoria's Bomb (1967), dieron el pistoletazo de salida (Bowser y Croxall, 2010: 12) a un tipo de narrativa donde la especulación ucrónica de corte victoriano se combinaba con la novela de aventuras. Más tarde, ya a finales de los 70 y en los 80 , tendrá lugar el establecimiento de forma más o menos canónica de unas directrices narrativas que encaminarán al steampunk a su propia toma de conciencia como forma literaria, a través de los mencionados Kevin W. Jeter (Morlock Night, 1979; Infernal Devices, 1987), Tim Powers (The Anubis Gates, 1983) y James P. Blaylock (Homunculus, 1986). En los 90, William Gibson y Bruce Sterling, con The Difference Engine (1990), darán forma a una de las obras cumbre del género, donde la deriva hacia el protagonismo de lo tecnomecánico será ya más que evidente. A partir de entonces es posible asistir, en palabras de VanderMeer y Chambers (2011: 60 y ss.), a cierto parón tanto en la calidad como en la producción, si bien en 1995 aparecerán tres textos que retomarán los presupuestos narrativos del steampunk de corte clásico: Steampunk Trilogy, de Paul Di Filippo; The Diamond Age, de Neal Stephenson, y Northern Lights, de Philip Pullman. No obstante, con la llegada del nuevo siglo el género asistirá a un resurgir como consecuencia, entre otros factores, de la incorporación de escritoras como Cherie Priest, Gail Carriger o Ekaterina Sedia (VanderMeer y Chambers, 2011: 49-63), o del salto al mainstream a través de diferentes formatos como el cómic o el cine, lo que supuso su difusión popular (Kiehlbauch, 2015: 90).

Casi desde sus orígenes, el steampunk ha trascendido los cauces de un mero patrón narrativo para pasar a convertirse en una fórmula de discurso cargada en mayor o menor medida ideológicamente. Así, desde la crítica a la racionalidad (Maiolino Herschmann, Pegoraro y Sanmartin Fernandes, 2013: 220) hasta el análisis de la tensión entre esta y la alienación proveniente de los avances de la tecnología (Pegoraro, 2012b:393), pasando por el rechazo al circuito mainstream y al consumo exacerbado (Pegoraro, 2012b: 399), o por la reflexión sobre la obsolescencia de los tiempos actuales (Sterling, 2009: 30), por citar algunos ejemplos, el steampunk, por encima de todo, ha intentado desarrollar un discurso crítico desde la visión de la tecnología actual como algo ofensivamente impermeable a nuestras vidas diarias, buscando así regresar a una época en la cual —en opinión de los steamers - las máquinas fueran "visible, human, fallible, and, above all, accesible" (Onion, 2008: 145) y mostrando una visión crítica acerca de 
la presencia de la tecnología hoy en día, y de cómo interactuamos con ella. En este sentido, el steampunk advierte que la cultura de la especialización habría alejado al hombre del conocimiento sobre el funcionamiento de las máquinas. De igual modo, frente a la obsolescencia, este retrofuturismo buscaría la sostenibilidad (Beard, 2014: XXIV-XXV), al tiempo que se pretende llevar al lector a pensar reflexivamente acerca de la historia, y de cómo esta se (re)configura, desde el prisma actual (Jagoda, 2010: 63). En resumen, y en palabras de Womack (2014: 412), nos encontramos ante algo más que un mero género narrativo: "sería una respuesta contra la deshumanización de cierta ciencia ficción supratecnológica [...] a esto se le debe añadir un espíritu contrario al consumismo, y una vocación clara por retomar el control, tecnológico y artístico, sobre las máquinas".

De este modo, el steampunk ha desarrollado una proyección social que sobrepasa, con mucho, a la de otros (sub)géneros literarios, llegando al punto de que muchos de sus seguidores ni siquiera proceden de la cultura literaria: "many of the people who today call themselves Steampunks have not read literature, taking cues instead of history, visual media, and the original fashionistas who sparked the subculture in the 1990s (VanderMeer y Chambers, 2011: 9). En este sentido, eventos como la Oxford's Steampunk Exhibit o el Burning Man Festival contribuyen a crear un sentimiento de comunidad entre sus seguidores que emana de inquietudes, filias y contextos de muy diversa naturaleza, pero que tienen en común una fuerte inclinación hacia lo steampunk, al margen de que esta sea consecuencia del bagaje libresco o del gusto por una moda tan efímera como estimulante: "steampunk is a vibrant culture of DIY 3 crafters, writers, artists, and other creative types each with their own slightly different answer to that question" (Collection of People, 2007: 6). Esta "creative community", en palabras de Goh (2009: 21), plantea un revisionismo histórico que unas veces se queda en el mero ornato de la moda y otras profundiza en las carencias de la sociedad contemporánea. Sitios colaborativos como www.etheremporium.pbwiki.com (Klaw, 2015: 350), por citar tan solo un ejemplo, no hacen sino poner de manifiesto que el steampunk se ha convertido en una tendencia multiforme donde convergen diferentes afinidades ante cierto retrofuturismo.

\footnotetext{
${ }^{3}$ Siglas para Do It Yourself.
} 


\section{ELSTEAMPUNK: HIBRIDECES Y RESIGNIFICACIONES DESDE LA POSMODERNIDAD}

\subsection{Un género híbrido}

La naturaleza híbrida y transfronteriza del steampunk surge, entre otras cuestiones, de su complicada adscripción genérica, donde la alternancia entre lo fantástico y la ciencia ficción genera problemas tanto ontológicos como pragmáticos: "la lógica de lo fantástico se inmiscuye en un paradigma epistemológico propio de la ciencia ficción, lo cual responde, de alguna forma, a la disolución de categorías o fronteras a la que tiende un género como el steampunk" (Conte Imbert, 2011: 264). En realidad, el género no hace otra cosa que proyectar en el mundo actual, tal y como señala Matangrano (2016: 259-260), el viejo debate decimonónico entre tecnología y cientificismo, por un lado, y el componente místico / sobrenatural / fantástico por el otro, a partir de una postura conciliadora o, cuando menos, integradora. De igual modo, las coordenadas temporales generan otra mixtura, al combinar era victoriana con visión proyectiva desde el prisma de la contemporaneidad. Y así, la fascinación por un futuro que surge de lo retro, a partir de una óptica de corte ucrónico, genera una transgresión negociada entre pasado, presente y futuro (Pegoraro, 2012b: 395) que emana de la cultura punk. Y es precisamente el "imaginar un futuro que no ocurrió para ese pasado" (Pegoraro, 2012a: 87), a partir de la pregunta ¿y si...?, lo que lleva a la combinación de fantasía y realidad, de hechos históricos y personajes ficticios, en una suerte de temporalidad híbrida (Bowser y Croxall, 2010: 2) que trasciende el plano puramente cronológico, semántico y genérico, al propiciar, desde la transversalidad, creaciones artísticas en las cuales se integran elementos heterogéneos procedentes de referentes culturales dispares (Hale, 2013: 11), dando lugar a un eclecticismo que permea cualquier tipo de manifestación artística.

\subsection{El steampunk y su semiótica / retórica}

En opinión de algunos críticos, el steampunk puede servir como piedra angular para entender las cuestiones centrales de los estudios retóricos del siglo XXI. En efecto, nos encontramos ante un género que hemos de concebir no solo como un estilo, sino también como un conjunto 
de ideas y creencias comunicadas a través de la literatura, el cine, el arte, la moda o el diseño, y que contribuyen a reforzar el sentimiento identitario de una determinada comunidad que ve así reflejados sus valores (Beard, 2014: XV-XVI, XXX). Y así, partiendo de la idea de que el steampunk "represents a rebellion against the mass-produced, cold, inaccessible technology that has infiltrated our lives and the apathetic society that it has contributed to" (Kiehlbauch, 2015: 100), el género construye, a partir de las más diversas manifestaciones, complejas y co-produtivas relaciones material-semióticas:

The potential and conventional use of a material is produced by its history and its accumulation of stories about how that material has been, cannot be, or might be used [...] This entanglement of expressive media, where text, object, and action meet - the material-semiotic- is of immense importance to understanding how individuals and communities produce, maintain, and modulate meaning through expressive forms and practices (Hale, 2013: 30-31).

De este modo, el steampunk se inserta en unas coordenadas donde posmodernidad y Romanticismo se combinan para recrear el pasado (Wright, 2014: 100). Y es precisamente este mecanismo de evaluación crítica de la historia - o al menos de la historia que nos ha llegado - lo que hace del género una creación posmoderna (Thompson, 2014: 131), en la cual el empleo de técnicas como la ironía, la intertextualidad, la hibridación, el pastiche o el anacronismo estratégico sirven para desfamiliarizar tanto el pasado victoriano como el presente de la globalización (Jagoda, 2010: 48). Cuando los artistas steampunk crean retro-máquinas contribuyen a gestar un mecanismo de reflexión sobre la tecnología moderna (VanderMeer y Chambers, 2011: 205), a partir de una visión alternativa del presente que es en el fondo una reformulación del futuro hecha desde un pasado optimista. De igual modo, el uso de personajes históricos en esta narrativa sirve para deconstruir una realidad puesta en entredicho desde el retrofuturismo. Y todo ello no hace sintonizar con una filosofía posmoderna que, como apunta González Rodríguez (2008: 144), "parte de la base de que las estructuras reflejan modos de pensar y de entender la realidad y, consecuentemente, considera que el orden de la narrativa revela y perpetúa el orden y los valores sociales, morales y políticos establecidos". La revisión intertextual —continúa González Rodríguez (2008: 144)— y "paródica de los 
géneros tradicionales se ha convertido en una estrategia que los escritores posmodernos utilizan para ocuparse de los problemas relacionados con la autoridad, la representación y la identidad". En este sentido, el steampunk, con sus constantes guiños a personajes y períodos históricos, así como a distintos géneros literarios, adquiere conciencia de su propia ficcionalidad (Womack, 2014: 411) y juega con la idea derriniana de los límites difusos de los textos, y con su naturaleza reticular, deconstruyendo un pasado cargado ideológicamente, sobre el que se superpone, a modo de metáfora, la pátina de un futuro alternativo, mostrando así, desde una perspectiva crítica, la relatividad de un presente puesto una y otra vez en entredicho. Esa destrucción del pasado canónico que otorga el universo victoriano sirve, por tanto, para analizar nuestras asunciones ideológicas en torno a conceptos como el de modernidad o civilización, por mencionar solo dos ejemplos. El steampunk, así, juega a crear una líquida comunicación entre el interior y el exterior del texto, desmontando y evidenciando las "fuerzas no controladas" (Regidor Nieto, 2011: 136) instituidas por la literatura y la historia.

Dentro de las relecturas llevadas a cabo por el steampunk, como es obvio, la resignificación del mundo decimonónico es crucial. De este modo, la combinación de estética victoriana, personajes históricos y narrativa futurista (Fernández, 2011) sirve para insertar en el siglo XIX valores y características tecnológicas contemporáneas (Maiolino Herschmann, Pegoraro y Sanmartin Fernandes, 2013: 226). Ese ¿qué habría ocurrido si...?, a propósito de la tecnología, abre una línea temporal que sirve para visualizar el pasado desde un presente que lo reinventa (Pegoraro, 2012b: 399), creando una relación dialéctica entre ambos períodos temporales a partir de la paradoja que genera la nostalgia por un pasado inexistente (Prieto Hames, 2016: 96): "steampunk brings a twenty-first century sensibility - a more questioning eye - to the Victorian Era" (Thompson, 2014: 131). Por ello, las ansiedades culturales actuales son exorcizadas a través del siglo XIX, como consecuencia del reconocimiento en tal época de problemas muy similares a aquellos a los que nos enfrentamos en el siglo XXI (Womack, 2014: 414). La reactualización del mundo decimonónico no solo le da vigencia, otorgándole una nueva semántica, sino que contribuye a reanalizar pasado y presente desde una óptica posmoderna. 


\title{
3. SEMIÓTICA DEL OBJETO EN EL UNIVERSO STEAMPUNK
}

\subsection{El objeto y su naturaleza metafísica en el mundo capitalista desde la óptica clásica}

La incorporación del término fetiche en Europa "para describir supuestas creencias en objetos que almacenaban el poder de los dioses" ha permitirlo convertirlo en sinónimo de engaño, ilusión o falsa conciencia (Blázquez, 1995-1996: 155-156), pero también constatar procesos de "sacralización del objeto que adquiere cualidades taumatúrgicas" (Salvador Peris, 2009: 140). Para Marx (1971: 36-47), la mercancía, en el mundo capitalista, habría adquirido una fetichización fruto del engaño surgido al parecer que emana del propio objeto la relación socioeconómica que este genera por haber sido producido por el hombre. Este hecho convierte al objeto en algo metafísico, habiendo así una traslación de la actividad productiva del hombre hacia el objeto mismo:

\begin{abstract}
El carácter misterioso de la forma mercancía estriba, por tanto, pura y simplemente, en que proyecta ante los hombres el carácter social del trabajo de estos como si fuese un carácter material de los propios productos de su trabajo, un don natural social de estos objetos y como si, por tanto, la relación social que media entre los productores y el trabajo colectivo de la sociedad fuese una relación social establecida entre los mismos objetos, al margen de sus productores (Marx, 1971: 37).
\end{abstract}

De este modo, la relación entre objetos materiales encubriría una relación social surgida del capitalismo, recordando, para Marx (1971: 38), a los procesos psicológicos que desencadena la religión, “donde los productos de la mente humana semejan seres dotados de vida propia, de existencia independiente, y relacionados entre sí y con los hombres". Trasladando esto a las formas de producción modernas, "si los objetos útiles adoptan la forma de mercancía es, pura y simplemente, porque son productos de trabajo privados independientes los unos de los otros" (Marx, 1971: 38). Y así, los productos del trabajo adquirirían una naturaleza fetichista que parecería desvincularlos de sus creadores y que no ocurría en la Edad Media, donde los vínculos personales de sujeción no hacían necesario "que los trabajos y los productos revistan [...] una 
forma fantástica distinta de su realidad" (Marx, 1971: 42). Todo esto, en suma, lleva a una subordinación del hombre al proceso de producción, sustentada en un "fetichismo adherido al mundo de las mercancías", esto es, a la "apariencia material de las condiciones sociales de trabajo" (Marx, 1971: 46). Y así, el fetichismo de la mercancía, en Marx, sustituiría a la religión del Antiguo Régimen, a partir de "la idea de un dios oculto en la intimidad de la mercancía" (Margulis, 2006: 32), lo que llevaría a "la dominación social por las cosas, no por los individuos" (Angulo Tarancón, 2017: 78), como consecuencia de la enajenación en el sistema capitalista. El fetichismo, en suma, cosifica al sujeto, haciendo que sean las mercancías "las que terminan dirigiendo la economía sin el menor control de los seres humanos, pareciendo así una relación social entre los objetos, al margen de quienes los producen" (Arkotxa Sarralde, 2019: 39), convirtiendo las relaciones sociales entre los hombres en una aparente relación entre cosas, "un producto social que, sin embargo, ha eliminado de sí todo rastro de trabajo humano [...] La mercancía es una forma del producto del trabajo humano que, sin embargo, no aparece como tal, sino como un objeto independiente del productor" (Morales Bonilla, 2018: 260). La mercancía - que no deja de ser, en el fondo, la codificación en clave capitalista y desde el prisma del fetichismo del producto del trabajo-, de este modo, aparece desvinculada de su productor, como consecuencia del pago de un salario (Larsson, 2014: 60), convirtiéndose en una forma de relación social.

Desde otro prisma, Walter Benjamin (1985: 11-13) sustenta la estructura religiosa del capitalismo sobre cuatro pilares: a) su condición de religión de culto, donde todo cobra significado solo en relación con la propia práctica; b) la naturaleza permanente del culto; c) el hecho de que el capitalismo no expíe la culpa, sino que la engendre, y d) el requisito de que su Dios permanezca en todo momento oculto. Ello conduciría, pues, al sujeto, según el filósofo alemán, a su propia destrucción, a partir de una religión con culto, pero sin dogma, de naturaleza totalizadora y donde el impío aparece representado en la figura del sujeto no productivo. A diferencia de Marx, para Benjamin la fetichización de la mercancía surge no ya de su presencia en el mercado sino de su naturaleza exhibicionista (Pérez Díaz, 2018: 183), a partir de un contexto productivo donde "la capacidad de disfrute de la materialidad de las cosas independientemente de su valor de cambio se ha perdido a todas vistas" (Zamora, 1999: 139). 


\subsection{Relación sujeto-objeto desde el prisma steampunk}

La cultura steampunk, más que su propio universo literario como tal, ha adquirido desarrollo en gran medida a partir de prácticas e iniciativas centradas en el mundo del objeto (Onion, 2008: 139). Y esto es precisamente lo que define la estética tecno-mecánica de dicho retrofuturismo: el conocimiento de cómo funciona algo (Brummett, 2014a). Por otro lado, los objetos son vistos también como símbolos que comportan significados en múltiples formas: pueden reescribir el pasado, reestructurar relaciones de poder, exhibir diferentes clases de interacciones sociales y culturales, etc. (Wright, 2014: 95-96, 108). En consonancia con ello, y frente a la figura del científico loco, el steampunk se servirá del reparador, del tinkerer, para mostrar el poder humano a la hora de crear invenciones útiles y beneficiosas, las cuales serán descritas con profusión de detalles en una narrativa donde se reescriben relaciones más éticas con los objetos que las que evidenció el período victoriano, período este que, sin embargo, contribuyó a la democratización de un dominio tecnológico puesto luego tan solo en manos de especialistas (Forlini, 2010: 74, 80).

De este modo, la coexistencia, en opinión de los especialistas, del boom del steampunk con la preeminencia de la tecnología — con la consiguiente incapacidad para controlarla / entenderla / modificarla-, en los últimos veinte años (Bowser y Croxall, 2010: 16-17), no hace sino poner de manifiesto la necesidad de un reencuentro con la naturaleza física de las cosas a partir de objetos y piezas presentes de forma más o menos recurrente en el imaginario retrofuturista: dirigibles, engranajes, relojes, máquinas a vapor, gafas protectoras, tuercas, etc. (Barratt, 2010: 175). Y así, frente a un mundo digital críptico e inaccesible, el steampunk recurre a la vieja artesanía para trabajar con tecnologías arcaicas, mirando al pasado mientras se rechazan elementos negativos de la modernidad, como la obsolescencia: "steampunks want to buy something once and then pass it on to our children. Even better, we want to make something once, something that we will use every day for the rest of our lifes [...] something that no one else in the world has" (VanderMeer y Chambers, 2011: 218).

Para entender el valor de los objetos en el imaginario steampunk es necesario, por tanto, ser consciente del componente afectivo que 
comporta $^{4}$, aumentado por el propósito estético que persiguen esta clase de creaciones (Prieto Hames, 2016: 108), y que encontramos en prácticas como el modding, consistente en reconstruir tecnología actual añadiendo ornamentos steampunk (Kiehlbauch, 2015: 93). De este modo, la cultura y el ethos del Do It Yourself conllevan un fetichismo tanto por los objetos pequeños (engranajes, etc.) como por los dispositivos de ingeniería de enormes proporciones (Brummett, 2014a: 82), que conduce, irónicamente, a huir de la reificación del individuo, en la medida en que el componente artesanal rehumaniza la relación entre hombre y objeto, generando así una re-fetichización o neo-fetichización contracapitalista (deconstructiva) del objeto.

En conclusión, el steampunk, en cuanto género posmoderno, resignifica la relación sujeto-objeto, en oposición al sistema productivo industrial, anulando el componente relacional, economicista, de la fetichización según el prisma marxista de la mercancía, en la medida en que tiende al consumo propio, a la no-venta, del objeto creado / manipulado. Por ello, nos hallamos ante un género donde el fetichismo de los objetos no emana de su componente productivo y relacional, como en el sistema capitalista, sino de su vínculo con el creador-manipulador, sin que la apropiación del trabajo ajeno, en términos comerciales, tenga lugar, por lo general. Frente a la obsolescencia y los dictados de la moda, el steampunk lucha por ofrecer elaboraciones materiales imperecederas y atemporales. Frente al intercambio y la reproducción constante del mismo proceso de producción y compraventa (Arkotxa Sarralde, 2019: 52), el steampunk rescata el valor lúdico, hedonista y recreativo de los objetos, vinculados indisolublemente a su creación y al responsable de esta. Y así, el steampunk subvierte - deconstruye - el sentido capitalista del fetichismo del objeto - mercancía con valor de cambio-, transformando la creación en algo propio, artesanal, inalienable, intransferible y con propiedades casi mágicas. Si en el capitalismo se desvían los afectos del valor de uso hacia el valor de cambio (Zamora, 1999: 141), mostrando las cosas como desprovistas de historia e independizadas de su creador (Morales Bonilla, 2018: 265), el steampunk desvincula las producciones de significaciones

\footnotetext{
${ }^{4}$ Así, en palabras de Onion (2008: 138-139): "Steampunk seeks less to recreate specific technologies of this time than to re-access what they see as the affective value of the material world of the nineteenth century".
} 
economicistas, incidiendo en el cordón umbilical que une a estas con su demiurgo.

\subsection{Análisis de un ejemplo: el reloj}

\subsubsection{El tiempo como símbolo operacional. Relojes y fetichismo steampunk}

La incorporación del tiempo a la literatura, en sus diversas dimensiones, ha permitido constatar, entre otras cuestiones, la contraposición entre el carácter subjetivo de este y el enfoque cosmológico tradicional (Udías Vallina, 2014: 28), llevando, en última instancia, a una consideración del tiempo y la temporalidad como "procesos relacionales [...] la relación con la alteridad es una conditio sine qua non para que ambos se den [...] Una conciencia absolutamente sola y vacía es una conciencia atemporal que no puede distinguir un momento de otro" (Garrido-Maturano, 2014: 41). De este modo, la relación con el Otro y la constatación de las dimensiones de pasado, presente y futuro emanan de la noción de temporalidad (Garrido-Maturano, 2014: 41), la cual a su vez "no se apoya en ningún órgano sensorial", siendo "imprescindible para realizar operaciones en el espacio [...] y para poder planificar acciones a futuro" (García-Borreguero, 2014: 67).

En el imaginario steampunk, el reloj comporta dos elementos cruciales que le otorgan un claro protagonismo: a) desde el punto de vista físico, el reloj tradicional, con sus engranajes y mecanismos ${ }^{5}$, es un dispositivo reparable, modificable y que rehúye la obsolescencia del fungible universo digital; b) desde el prisma cultural, la visión posmoderna que otorga este género permite deconstruir el valor simbólico del reloj en las sociedades modernas - vinculado a la medición de las jornadas de trabajo y a la cuantificación de cualquier período vital—, creando una fetichización en torno a él que se encuentra a caballo entre la recreación lúdico-estética ante la perfección del mecanismo ${ }^{6}$ y la denuncia por

\footnotetext{
${ }^{5}$ Los engranajes son, sin duda, uno de los elementos visuales y narrativos más frecuentes y reconocibles en el steampunk, como ha señalado Womack (2014: 411), junto con las turbinas a presión, los autómatas, las máquinas del tiempo o los dirigibles, por citar algunos ejemplos.

${ }^{6}$ Véanse, por ejemplo, las propias confesiones autobiográficas de autores como Blaylock o Jeter acerca de la fascinación que sobre ellos siempre han ejercido las maquinarias de los relojes o los
} 
la alienación que comporta la obsesión por el tiempo en las sociedades contemporáneas (post)industriales.

En efecto, el reloj no es más que la representación simbólica de una preocupación por el tiempo que, en el caso del steampunk, resulta clave (Moreno, 2010: 263), y que en ocasiones se manifiesta a través de las estrategias de los viajes en el tiempo ${ }^{7}$ y los universos paralelos - "sometimes steampunk imagines the course of social and scientific development of Age of Steam technologies and aesthetics in parallel universes" (Brummett, 2014b: X)—, lo que desencadena una nueva temporalidad que rompe con el concepto del devenir lineal, poniendo a prueba la capacidad del lector para enfrentarse a situaciones narrativas donde los anacronismos y las paradojas temporales llevan a situaciones límite, en ocasiones, la verosimilitud de las historias (Bowser y Croxall, 2010: 10). De este modo, el tiempo objetivo y el reloj, que han cobrado una nueva dimensión con el capitalismo, se ven subvertidos y resignificados en el steampunk, al establecerse una relación íntima y no-comercial entre objeto y sujeto, encarnada en la presencia de un reloj que sirve tanto como referente material - en claro homenaje a la cultura maker antidigital- y como elemento simbólico que deconstruye el valor cultural del tiempo en la sociedad moderna.

\subsubsection{El reloj como elemento narrativo en el universo steampunk: algunas muestras}

La presencia del reloj en las obras de inspiración más o menos steampunk ha sido una constante desde sus orígenes, y con frecuencia vinculada a la figura del inventor / creador / reparador. Sin ir más lejos, ya en la primera edisonada - The Huge Hunter; or, the Steam Man of the Prairies (1868), de Edward S. Ellis_-, su protagonista, un enano jorobado, tiene un don para los inventos "con elementos en su haber como un reloj que siempre se mantiene en hora" (Nevins, 2015: 10). Desde entonces, la alternancia y combinación entre máquinas, engranajes, inventores y relojes ha sido una constante, intensificándose este recurso en los últimos años.

engranajes antiguos (VanderMeer y Chambers, 2011: 49, 53).

${ }^{7}$ Una obra ya clásica dentro del imaginario steampunk sobre los viajes en el tiempo es The Anubis Gates (1983), de Tim Powers. 
Como muestras, podemos citar, dentro de la antología en español de Ann y Jeff VanderMeer (2015), desde las referencias a los dispositivos mecánicos, ya en los títulos de los relatos - "La máquina de Lord Kelvin", de James P. Blaylock (2015) - , hasta la simbología de los engranajes y las manivelas en "La boca dadivosa", de Ian R. MacLeod (2015) — "ruedas dentadas dentro de ruedas dentadas; mundos dentro de mundos" (MacLeod, 2015: 77) —, o en "El hombre de vapor de la campiña y el jinete oscuro se ven las caras: una novela barata", de Joe R. Lansdale (2015) — "la mayor parte de su maquinaria funcionaba a base de engranajes, cables y ruedas dentadas de bicicleta [...] los morlocks [...] pedaleaban sobre ruedas dentadas y engranajes conectados y permitían a su líder morlock [...] manipular manivelas y guiar los mecanismos" (Lansdale, 2015: 132) - , pasando por el protagonismo de los inventores / creadores en "El dios payaso se acerca", de Jay Lake (2015) o en "Setenta y dos letras", de Ted Chiang (2015). Sin embargo, serán sobre todo las referencias al tiempo ${ }^{8}$ — “el tiempo está contenido entre, dentro de y tras cortinas dimensionales, y esas cortinas son fuertes y difíciles de romper" (Lansdale, 2015: 126) - las que permitan incorporar el protagonismo del reloj casi como un personaje más en las historias de corte steampunk, a partir de un fetichismo que aparece delatado por descripciones que se deleitan en los más minuciosos detalles del objeto: "consultó su reloj de bolsillo, dorado, grueso como una galleta, que llevaba impresos zarcillos y hojas que, enroscándose, formaban las iniciales V. R." (Chabon, 2015: 231); "tras sacar un reloj grande y redondo del bolsillo del chaleco, Cowperthwait lo sincronizó con el ómnibus de Tooting de las 11:45" (Di Filippo, 2015: 244), etc.

En el caso de la literatura steampunk en español es posible constatar también el uso fetichista del reloj, con diversas intencionalidades. Así, por ejemplo, en "El óxido del sombrerero", de Alfredo Álamo (2014), el juego intertextual que propicia Alicia en el país de las maravillas permite reescribir el célebre librito mediante la construcción de un protagonista que se ajusta a dos clichés frecuentes en esta narrativa de corte retrofuturista, esto es, la obsesión por la medición del tiempo y la configuración del cerebro como una máquina-reloj steampunk más: "al sombrerero le molestaba sobremanera que le hicieran perder el hilo del tiempo [...] y los engranajes

\footnotetext{
${ }^{8}$ Consúltese la obra de Palma (2009) para constatar las innumerables referencias filosóficas de narrador y personajes sobre esta cuestión.
} 
de su cerebro no podían concebir un mísero segundo de retraso" (Álamo, 2014: 287-288). No en vano, el tiempo adquirirá tintes alegóricos a lo largo de la historia — "Sombrerero [...] del mismo Don Tiempo traigo noticias. Después de todo, nadie puede vivir demasiado lejos de él" (Álamo, 2014: 292) — , lo cual no hace sino sumarse a la archiconocida frase del Señor Conejo, que adquiere una nueva interpretación en la versión retrofuturista del texto de Carroll: “¡Tarde, llego tarde!” (Álamo, 2014: 293). Por último, en el desenlace de la obra, la muerte del sombrerero se teñirá de una trágica ironía en labios del gato, a partir de una broma macabra en torno de nuevo a la idea de tiempo: "al parecer el tiempo no perdona. Y todos junto a la mesa rieron su broma" (Álamo, 2014: 296). De cualquiera de las maneras, la presencia del reloj, y la recreación en su aspecto físico, destaca de forma muy llamativa, y solo se hace comprensible a partir de la confluencia entre el relato original y el imaginario steampunk: "su enorme reloj de bolsillo" (Álamo, 2014: 287); "el momento de aguja pequeña seis y aguja grande doce más uno" (Álamo, 2014: 287, 295); "su otro reloj, lleno de mantequilla cara y migas variadas" (Álamo, 2014: 288); "el ruido de su relojería girando a gran velocidad" (Álamo, 2014: 291); "un sonoro Tic" (Álamo, 2014: 295); "estiró de la cadena que lo sostenía y lo levantó" (Álamo, 2014: 295); “Tac, concluyó el reloj” (Álamo, 2014: 295), etc.

Otro ejemplo muy significativo es el de "Como dentro de un reloj”, de Luis Guallar (2014). Lo que nos encontramos aquí es un relato-descripción acerca de un edificio automatizado cuyo correcto funcionamiento es exclusiva responsabilidad de un grupo de autómatas y de un conjunto abigarrado de máquinas. El argumento gira en torno a una serie de ruidos extraños que por las noches despiertan al protagonista, produciendo así en el lector un sentimiento de angustia que va in crescendo, fruto del convencimiento, por parte del personaje principal, de que "el edificio, aquel cúmulo de mecanismos y extraños inventos disfrazado de hotel, sería mi tumba" (Guallar, 2014: 332). Y así, los extraños ruidos nocturnos, interpretados como "respiración apagada" o "voz amortiguada" (Guallar, 2014: 333), llevarán al protagonista a la locura y a su ingreso en un hospital, donde no logrará escapar a los demonios y fantasmas del edificio que le arrastró al desvarío: "es durante las oscuras y terribles noches $[. .$.$] cuando puedo escuchar el infernal traqueteo mecánico de$ cientos de engranajes, palancas y válvulas que surgen de detrás de las paredes, y me hacen sentir como si estuviese encerrado en el interior de un 
gran reloj" (Guallar, 2014: 339). De este modo, en el relato de Guallar, el edificio automatizado acaba por convertirse en una metáfora del reloj, y el enloquecimiento del protagonista, atrapado en él - "la algarabía de ruedas y engranajes que convertía la oscuridad de mi dormitorio en una opresiva tumba encerrada en el interior de un gran reloj" (Guallar, 2014: 330)-, no es sino una angustiosa y literaria reflexión acerca del poder alienante del tiempo — y de la obsesión por su medición y control— en la sociedad moderna, y de su naturaleza absorbente:

El murmullo mecánico y constante de las ruedas dentadas girando unas contra otras, moviendo válvulas y palancas, me hacía sentir como si estuviese dentro de un reloj, que con su incesante tic-tac me acunaba mientras las agujas, moviéndose al ritmo del sonido, me llevaban a sumergirme en las cálidas aguas del sueño (Guallar, 2014: 323).

De cualquiera de las maneras, sin duda una de las obras paradigmáticas en lo que a la fetichización del reloj concierne es La invención de Hugo Cabret, de Brian Selznick (2007). Sin ser esta una obra netamente steampunk, muestra de forma evidente sus deudas para con este género retrofuturista a través del imaginario mecánico del que se sirve y que nutre la trama argumental — con autómatas, relojes, resortes y engranajes salpicando de forma continuada la historia-, de la combinación entre realidad y fantasía, del período histórico que abarca — comienzos del siglo XX, asumido con frecuencia como una elongación del período victoriano-, del uso de figuras asociadas al universo steampunk, como el cineasta Georges Méliès y, sobre todo, de la preeminencia de la figura del inventor / reparador, clave a propósito del personaje principal del relato.

La obra, de difícil adscripción genérica - la presencia continuada de dibujos y fotografías imprimen un cierto ritmo cinematográfico a la narración (Silva Cordeiro y Delácio Fernandes, 2016: 152) y sitúan el volumen a caballo entre el álbum ilustrado y la novela gráfica-, cuenta la historia de un muchacho huérfano, Hugo, a quien el fallecimiento de su tío alcohólico, tras el de su padre inventor, le convierte en improvisado mantenedor de los distintos relojes que pueblan la estación de tren de Montparnasse, en París. En su camino se cruzarán una niña y el padrino de esta, que no resultará ser otro que el cineasta retirado Georges Méliès, quien regenta en la actualidad una tienda de juguetes y golosinas. El afán 
de Hugo para recuperar un autómata escritor conservado de su padre y el descubrimiento de que el anciano de la tienda de juguetes no es otro que el gran Méliès articulan una historia donde texto e imagen alternan entre toda suerte de relojes y dispositivos mecánicos que acompañan al lector, como un personaje más. La obra, destinada al público juvenil, muestra la búsqueda por parte de Hugo de su identidad en el camino a la madurez, para quien la recuperación de la figura paterna pasa por los vínculos materiales - un cuaderno de anotaciones y el autómata- y emocionales - el gusto por las máquinas, los inventos o el cine - que le unen a él (Silva Cordeiro y Delácio Fernandes, 2016: 152-157). De este modo, la novela, a diferencia de la mayoría de los textos de esta clase —que poco contribuyen a aumentar el espíritu crítico, inventivo y estético de los jóvenes-, crea una narración de calidad donde los miedos, ansiedades y problemas de un niño en su camino a la adolescencia (Silva Cordeiro y Delácio Fernandes, 2016: 159) se combinan con un seductor imaginario steampunk que atrae a niños y adultos desde las primeras líneas.

En lo que al tema de este artículo concierne, lo primero que llama la atención es la omnipresencia de relojes en el relato - "un hombre que miraba muy atento el reloj principal" (Selznick, 2007: 204); "el único sonido que se oía era el pulso rítmico de la maquinaria de los relojes" (Selznick, 2007: 378)—, la cual convive con la obsesión de Hugo hacia estos: "le iba a ser imposible cuidar de los relojes" (Selznick, 2007: 307), "se preguntó cuándo dejaría de funcionar aquel reloj" (Selznick, 2007:371), etc. El fetichismo hacia estos surge de nuevo tanto de su pormenorizada descripción - “comenzó por los dos grandes relojes con esfera de cristal [...] eran como enormes ventanales" (Selznick, 2007: 76) — como del lazo familiar que le supone a Hugo: "provenientes de una larga estirpe dedicada a la cronometría" (Selznick, 2007: 125); "siempre pensó que acabaría por convertirse en relojero como su padre" (Selznick, 2007: 126), etc. A partir de ahí, la obra establece una serie de vínculos semánticos entre el reloj y los conceptos más diversos: a) el cine - "el año pasado vimos una en la que un hombre se quedaba colgado de las agujas de un reloj gigantesco" (Selznick, 2007: 173)—; b) el control del tiempo — "sabía que el tiempo seguiría su curso aunque se rompieran todos los relojes de la estación, por muchas ganas que tuviera de detenerlo" (Selznick, 2007: 378)—; c) el propio protagonista — "había apodado a Hugo 'Tictac' porque siempre llevaba algún reloj en los bolsillos" (Selznick, 2007: 146)—; d) la creación 
divina - "era un hombre construido enteramente con engranajes de relojería" (Selznick, 2007: 114)—; e) los lazos paterno-filiales — "A Hugo se le daba bien arreglar relojes; parecía una habilidad hereditaria en su familia" (Selznick, 2007: 116)—; f) la magia — "Hugo había llegado a comprender la conexión entre la cronometría y la magia de la que le había hablado su padre" (Selznick, 2007: 232)—- g) el corazón — “al ritmo de los latidos de su corazón, como el tictac de un reloj” (Selznick, 2007: 124)—; h) el cerebro - "a menudo imaginaba que tenía el cráneo lleno de ruedas y engranajes, y sentía una extraña conexión con todos los mecanismos que tocaba" (Selznick, 2007: 126) —; i) la madurez — “¿me estás diciendo que tú solo has podido mantener y revisar todos los relojes de la estación? ¿Sin ayuda? ¿Tú, un chaval de diez años? "(Selznick, 2007: 479)—; j) la creatividad - "sacó un trozo de papel y un lápiz de una caja que había junto a la cama y se puso a dibujar relojes y engranajes" (Selznick, 2007: 139)_, o k) la tranquilidad — "arrullado por el ritmo del reloj" (Selznick, 2007: 139)—, por citar algunos ejemplos.

Y así, cuando el propio autor, en las páginas finales de la obra, reconoce sus débitos para quienes le han asesorado en el ámbito de la horología — "Andy Baron [...] se pasó horas hablando por teléfono conmigo en su empeño por explicarme los aspectos técnicos de todo tipo de relojes" (Selznick, 2007: 529); "me ayudaron a adentrarme en los misterios de los mecanismos de relojería" (Selznick, 2007: 530)—, no hace sino evidenciar uno de los pilares cruciales de la obra, esto es, la importancia del reloj en cuanto objeto y de la reparación - "había logrado avanzar en el arreglo del hombre mecánico sin fijarse en los dibujos de su padre" (Selznick, 2007: 190); "se te daba bien reparar los juguetes estropeados" (Selznick, 2007: 224); “¿cuál es tu propósito en la vida? [...] ¿arreglar cosas? Hugo Reflexionó” (Selznick, 2007: 375) — en cuanto arte. El reloj, en efecto, lejos de ser tan solo un mero instrumento para la medición del tiempo, encarna la quintaesencia del culto steampunk a la mecánica y a los engranajes, revestidos de un fetichismo tan evidente que el lector no puede sustraerse a una fascinación que cautiva al protagonista una y otra vez: "se encontró rodeado de piezas mecánicas, más de las que jamás hubiera podido imaginar. Mirara donde mirara, encontraba botes llenos de piececitas metálicas, resortes minúsculos, engranajes, muelles, tuercas" (Selznick, 2007: 166); "los dos observaron cómo empezaban a moverse los engranajes de relojería [...] los mecanismos zumbaban, rotaban, giraban" 
(Selznick, 2007: 237); “una cascada de movimientos perfectos, con cientos de pequeñas acciones de brillante precisión, recorrió el interior" (Selznick, 2007: 140), etc. Esta fascinación-obsesión — “sus mecanismos eran tan intrincados, tan complejos, que se mareó solo de mirarlos" (Selznick, 2007: 117) - llevará de nuevo a crear vínculos semánticos, esta vez con la creación de vida - "cuando se aburría construía animalitos mecánicos" (Selznick, 2007: 116); “tal vez sea esa la razón de que las máquinas rotas resulten tan tristes: ya no pueden cumplir con el propósito para el que fueron creadas" (Selznick, 2007: 374) — o con el universo — "me gusta imaginar que el mundo es un enorme mecanismo" (Selznick, 2007: 378) , por citar dos ejemplos. Y, finalmente, este fetichismo hacia los objetos mecánicos encontrará su máxima expresión en la figura de ese autómata que se convertirá en una auténtica obsesión para Hugo - "se quedaba trabajando en el autómata hasta el amanecer" (Selznick, 2007: 191)—, en la medida en que representa el último vínculo que le queda con su difunto padre - “cuanto más avanzaba en su restauración, más le obsesionaba una idea [...] resolvería todas las preguntas que tenía pendientes y le revelaría qué hacer ahora que se había quedado solo" (Selznick, 2007: 133)—y lo único valioso de su vida: "el autómata yacía entre los restos del edificio como si quisiera acusar a Hugo, recordarle que todo lo que tenía en la vida había desaparecido [...] la idea de perder de vista al hombre mecánico se le hacía insoportable" (Selznick, 2007: 130, 138). De este modo, la consideración del autómata como un ser vivo más - "los dos empezaron a considerar al autómata como un animal herido que había que cuidar para que se restableciera" (Selznick, 2007: 121)— dará pie, por último, a un guiño metaenunciativo y diegético clave, al atribuir todo el relato que concluye ante nosotros a la capacidad inventiva y escrituraria del mecanismo reparado por el protagonista:

El autómata que descubrió mi padre acabó por salvarme la vida [...] He pasado innumerables horas diseñándolo. He tallado cada uno de sus engranajes, he troquelado todas sus ruedas dentadas y he dado forma con mis propias manos hasta a los detalles más nimios de su maquinaria.

Si se le da cuerda, hace algo que no creo que pueda hacer ningún otro autómata del mundo. Mi autómata es capaz de contar la increíble historia de Georges Méliès, su mujer y su ahijada, y el triste relato de un amable relojero cuyo hijo llegó a convertirse en mago.

La compleja maquinaria que está alojada en el interior de mi autómata 
es capaz de reproducir ciento cincuenta y ocho dibujos diferentes, y puede escribir letra por letra un libro entero compuesto de veintiocho mil ochocientas ochenta y nueve palabras.

Unas palabras que estáis acabando de leer en este preciso momento (Selznick, 2007: 510-511).

Como señalan Silva Cordeiro y Delácio Fernandes (2016: 157), al colocar al autómata de Hugo como el verdadero autor de la obra se lleva al lector, una vez más, al plano de la fantasía, evidenciando así el elemento metalingüístico presente en la narrativa. De cualquiera de las maneras, lo cierto es que la figura del autómata, en el texto, no hace sino exacerbar aún más el constante esfuerzo por otorgar a la mecanización, y al imaginario alrededor de engranajes, poleas y relojes, un protagonismo que solo se entiende desde el interés por proporcionar a estos dispositivos y objetos vínculos afectivos con un protagonista que, huérfano y desarraigado, ve en el mundo de la cronometría y de la reparación un mecanismo para exorcizar viejos fantasmas y recuperar la memoria de su padre, encontrando así de nuevo su lugar en el mundo y avanzando hacia la madurez de la vida adulta.

\section{CONCLUSIONES}

En un reciente ensayo, David Sax (2016) apuntaba la creciente importancia que, ante la saturación por la sobreexposición al mundo digital, está cobrando el universo analógico, retro o vintage dentro de cierto movimiento contrageneracional juvenil, el cual parece sobrepasar al análisis superficial que ve en este fenómeno un mero esnobismo hipster ante un pasado nostálgico que sirve solo como elemento diferenciador. Esta tendencia antidigital no hace sino sumarse a movimientos como el steampunk, que arrancan de una profunda añoranza por un pasado replanteado. Y así, el steampunk emerge como un género de difícil adscripción, a caballo entre la ciencia ficción y la literatura fantástica, y donde se reescribe un pasado ambientado a finales del XIX o comienzos del XX con una clara prelación del vapor y la mecánica sobre la electricidad / electrónica y los hidrocarburos. Retomando a visionarios como Verne o Wells, e inspirándose en subgéneros pulp como las edisonadas, autores como Michael Moorcock o Kevin W. Jeter comenzaron a crear en los años 70 y 80 del pasado siglo un universo narrativo que ha ido adquiriendo 
mayores dimensiones a medida que el género daba el salto a diferentes formatos o discursos - los videojuegos, el cine, el cómic, las películas de animación, los juegos de rol-, sumado al hecho de que, irónicamente, Internet y el mundo digital han contribuido a crear una comunidad de simpatizantes, especialistas y consumidores que ven en las convenciones o en los cosplay un mecanismo de refuerzo identitario. Al margen de su incierta evolución futura, lo que sí es constatable es el hecho de que parte del impacto del steampunk es consecuencia de las implicaciones ideológicas que el género ha ido asumiendo — crítica al capitalismo y a la obsolescencia, reivindicación de la artesanía, de la cultura del Do It Yourself... - y de los mecanismos semióticos que ha ido gestando, al desarrollar un discurso posmoderno que deconstruye las conexiones entre pasado y futuro, así como las relaciones que el capitalismo ha establecido entre el individuo y los objetos ${ }^{9}$, desde una hibridez que no le tiene miedo a la combinación de géneros, de realidad y fantasía, o de diferentes formatos y plataformas.

Uno de los aspectos aún no suficientemente estudiados a propósito del steampunk es lo concerniente a las relaciones sígnicas que este retrofuturismo establece entre el objeto y su creador / poseedor. Desde el análisis economicista clásico que ofrece la óptica marxista, el mundo capitalista ha convertido a los objetos en mercancía, creando un fetichismo en torno a esta que emana de la errónea atribución a la materia producida de unas relaciones socioeconómicas que, en última instancia, provienen del creador de la mercancía, esto es, de su productor. Esta situación de alienación, en virtud de la cual el sujeto se desvincula del producto

\footnotetext{
${ }^{9}$ Si bien el tema escapa a los objetivos de este artículo, en el caso de otros géneros cercanos, como el ciberpunk, por ejemplo, la crítica al capitalismo también se da, pero a través del retrato de un universo distópico en el cual el sujeto se ve "sometido a grandes corporaciones mundiales que ejercen un dominio absoluto" (Areco, 2011: 164). De este modo, y a diferencia del steampunk, el ser humano se encuentra sumergido, no ya en una atmósfera retro, sino en un capitalismo tardío donde las corporaciones globales abarrotan la Tierra de tecnología y desechos, mostrando así el impacto negativo del neoliberalismo en el medio ambiente y en el acceso a recursos (Leone, 2017: 68). Y así, frente a la relación hombre-máquina del steampunk, con un claro componente afectivo y artesanal, el ciberpunk muestra un universo deshumanizado donde tecnología y poderes totalitarios se alían, pasando del rol del individuo en cuanto orgulloso creador / inventor de objetos, respecto a los que sostiene una posición de alteridad, a una disolución de la frontera natural-artificial que comporta, en última instancia, el desarrollo de identidades difusas y en ocasiones alienantes en las que la unión hombre-máquina supone la aparición de biotecnologías que desencadenan la irrupción de un nuevo protagonista: el ciborg.
} 
elaborado, al tiempo que desaparece de las relaciones vertebradas en torno a la mercancía en circulación, genera una suerte de dinámica pseudorreligiosa donde, en palabras de Walter Benjamin (1985), el culto al consumo lleva a un círculo vicioso de autoinculpación del que solo escapa el impío, esto es, el sujeto no productivo.

Frente a todo ello, el steampunk, desde la posmodernidad, deconstruye y resignifica las relaciones entre sujeto y objeto, desarrollando un vínculo íntimo e individual con las creaciones, mientras desaparece - o pasa a una posición marginal - la utilización economicista de las cosas — de naturaleza mecánica — producidas por el individuo. Frente a la alienación e industrialización que comporta la producción despersonalizada en el contexto capitalista, el steampunk aboga por la reivindicación de la artesanía y la elaboración propia - respecto a la cual se crea un vínculo indisoluble-, desposeyendo a la producción y al consumo de objetos del sentimiento culpabilizador que surge en una economía de mercado. El objeto, así, deja de ser algo ajeno para su fabricante / inventor, el cual controla plenamente la producción de este a partir de un retorno al mundo analógico que otorga fisicidad al producto y que rechaza la especialización del universo digital. A partir de aquí, el reloj como objeto y como símbolo adquiere una especial relevancia en el imaginario steampunk, tanto por deconstruir la obsesión por la cronometría de la producción industrial y en cadena como por representar la quintaesencia de la perfección mecánica y la encarnación de la figura del reparador. Diferentes ejemplos —entre los que destaca sobremanera La invención de Hugo Cabret, de Brian Selznick (2007) - ilustran cómo, a lo largo de la historia del steampunk, el reloj ha adquirido una fetichización contracapitalista en la que individuo y objeto crean un vínculo fruto de un culto a la mecánica que surge como canto de cisne ante una sociedad donde el individuo permanece ajeno a la fabricación, comprensión o reparación de unos objetos estandarizados y condenados a la obsolescencia.

Así pues, sirvan estas líneas para reivindicar las sugerencias, estrategias semióticas y propuestas narrativas desarrolladas por un (sub) género poco atendido hasta ahora por la crítica española, pero sobre el que merece la pena centrarse a la hora de estudiar la proyección que sobre la narrativa, la sociedad y el arte actual está llevando a cabo esta propuesta retrofuturista que se sirve de la deconstrucción posmoderna para reescribir la realidad, aunando pasado y futuro a partir de un revisionismo que alerta 
de los peligros de la tecnología actual desde nuestro prisma como pasivos consumidores, mientras el discurso predominante ofrece una visión buenista y acrítica del mundo digital.

\section{REFERENCIAS BIBLIOGRÁFICAS}

ÁLAMO, A. (2014). "El óxido del sombrerero". En Retrofuturismos. Antología Steampunk, M. Womack (ed.), 287-296. Zaragoza: Ediciones Nevsky.

ANGULO TARANCÓN, M. (2017). "La dictadura del fetiche: de la objetividad del valor a la dominación sin sujeto". Éndoxa: Series Filosóficas 40, 77-102.

ARECO, M. (2011). "Bestiario ciberpunk: sobre el imbunche y otros monstruos en Ygdrasil de Jorge Baradit". Aisthesis 49, 163-174.

ARKOTXA SARRALDE, J. (2019). "El fetichismo de la realidad. Una interpretación de Agustín García Calvo a través de Marx y Nietzsche". Laguna. Revista de Filosofía 44, 35-57.

BARRATT, C. C. (2010). "Time Machines: Steampunk in Contemporary Art”. Neo-Victorian Studies 3.1, 167-188.

BEARD, D. (2014). "A Rhetoric of Steam". En Clockwork Rhetoric. The Language and Style of Steampunk, B. Brummett (ed.), XIV-XXXII. Jackson: University Press of Mississippi.

BENJAMIN, W. (1985). El capitalismo como religión, E. Foffani y J. A. Ennis (traducción notas y comentarios). Buenos Aires: Instituto de Investigaciones en Humanidades y Ciencias Sociales (IdIHCS) UNLP-CONICET, https://docs. google.com/viewer? url=http $\% 3 A \% 2 F \% 2 F w w w$.redkatatay. org $\% 2$ Fsitio $\% 2$ Ftalleres $\% 2$ Fcapitalismo_religion_5. $p d f \& p d f=$ true [06/11/2019].

BLAYLOCK, J. P. (1986). Homunculus. New York: Ace Books. (2015). "La máquina de Lord Kelvin”. En Steampunk, J. VanderMeer y A. VanderMeer (eds.), 25-60. Sevilla: Edge Entertainment.

BLÁZQUEZ, G. (1995-1996). "El fetichismo de la mercancía: ¿Una religión para el mundo moderno?". Estudios 6, 155-168.

BOWSER, R. A. y CROXALL, B. (2010). "Introduction: Industrial Evolution". Neo-Victorian Studies 3.1, 1-45. 
BRUMMETT, B. (2014a). “Jumping Scale in Steampunk. One Gear Makes You Larger; One Duct Makes You Small”. En Clockwork Rhetoric. The Language and Style of Steampunk, B. Brummett (ed.), 80-93. Jackson: University Press of Mississippi.

(2014b). "The Rhetoric of Steampunk". En Clockwork Rhetoric. The Language and Style of Steampunk, B. Brummett (ed.), IX-XIII. Jackson: University Press of Mississippi.

CHABON, M. (2015). "El agente marciano, un romance planetario". En Steampunk, J. VanderMeer y A. VanderMeer (eds.), 215-242. Sevilla: Edge Entertainment.

CHIANG, T. (2015). "Setenta y dos letras". En Steampunk, J. VanderMeer y A. VanderMeer (eds.), 169-215. Sevilla: Edge Entertainment.

CLARK, R. W. (1967). Queen Victoria's Bomb. London: Panther Books.

COLLECTION OF PEOPLE (2007). "What then, is steampunk? Steampunk is awesome". Steampunk Magazine 3, 6-7.

CONTE IMBERT, D. (2011). "El mundo de las ciudades oscuras, de Schuiten y Peeters: una topografía de la desubicación". Ángulo Recto. Revista de estudios sobre la ciudad como espacio plural 3.2, 247-277.

DI FILIPPO, P. (1995). Steampunk Trilogy. New York: Running Press. (2015). "Victoria". En Steampunk, J. VanderMeer y A. VanderMeer (eds.), 243-296. Sevilla: Edge Entertainment.

ELLIS, E. S. (1868). The Huge Hunter; or, the Steam Man of the Prairies. New York: The American News Co.

FERME, F. (2011). “Autonomía y cosificación: 'El carácter imaginario de la mercancía o su secreto"'. Intersticios. Revista Sociológica de Pensamiento Crítico 5.2, 35-61.

FERNÁNDEZ, L. (2011). "Llega por fin a España la novela 'steampunk"”. El Mundo, 6 de diciembre, http://www.siis.net/documentos/ hemeroteca/111206_12.pdf [25/10/2019].

FORLINI, S. (2010). "Technology and Morality: The Stuff of Steampunk". Neo-Victorian Studies 3.1, 72-98.

GARCÍA-BORREGUERO, P. (2014). “La percepción subjetiva del paso del tiempo". Crítica 990, 66-70.

GARRIDO-MATURANO, Á. E. (2014). "El tiempo, el mar y las estrellas. Sentido cosmológico, filosófico y religioso del tiempo". Crítica 990, 36-41. 
GIBSON, W. y STERLING, B. (1990). The Difference Engine. London: Victor Gollancz Ltd.

GOH, J. (2009). “On Race and Steampunk”. Steampunk Magazine 7, 1621.

GONZÁLEZ RODRÍGUEZ, L. M. (2008). "La deconstrucción del cuento de hadas: intertextualidad y feminismo en 'The Cloud' de John Fowles". Clepsydra: Revista de Estudios de Género y Teoría Feminista 7, 143-156.

GUALLAR, L. (2014). "Como dentro de un reloj". En Retrofuturismos. Antología Steampunk, M. Womack (ed.), 317-339. Zaragoza: Ediciones Nevsky.

HALE, M. (2013). "Airship Captains, Pith Helmets, \& Other Assorted Brassy Bits: Steampunk Personas and Material-Semiotic Production". New Directions in Folklore 11.1, 3-34.

HARRISON, H. (1972). A Transatlantic Tunnel Hurrah. New York: Putnam.

JAGODA, P. (2010). "Clacking Control Societies: Steampunk, History, and the Difference Engine of Escape". Neo-Victorian Studies 3.1, 46-71.

JETER, K. W. (1979). Morlock Night. New York: Daw Books. (1987). Infernal Devices. New York: St. Martin’s Press.

KIEHLBAUCH, S. (2015). "Man and Machine in the World of Steam: The Emergence of Steampunk as a Cultural Phenomenon". The Forum: Journal of History 7.1, 83-104.

KLAW, R. (2015). "La máquina del tiempo de vapor: un estudio de la cultura popular". En Steampunk, J. VanderMeer y A. VanderMeer (eds.), 349-358. Sevilla: Edge Entertainment.

LAKE, J. (2015). “El dios payaso se acerca”. En Steampunk, J. VanderMeer y A. VanderMeer (eds.), 103-114. Sevilla: Edge Entertainment.

LANSDALE, J. R. (2015). "El hombre de vapor de la campiña y el jinete oscuro se ven las caras: una novela barata". En Steampunk, J. VanderMeer y A. VanderMeer (eds.), 115-152. Sevilla: Edge Entertainment.

LARSSON, M. J. (2014). "Entre máscaras y espejos. Aspectos económicos y epistemológicos del fetichismo de la mercancía". EntreDiversidades: Revista de Ciencias Sociales y Humanidades 2, 45-67. 
LEONE, M. L. (2017). "Trans-species Collaborations in Response to Social, Economic, and Environmental Violence in Rosa Montero's Lágrimas en la lluvia and El peso del corazón”.Ecozon@: European Journal of Literature, Culture and Environment 8.1, 61-78.

MACLEOD, I.R.(2015). “Laboca dadivosa”. En Steampunk, J. VanderMeer y A. VanderMeer (eds.), 61-84. Sevilla: Edge Entertainment.

MAIOLINO HERSCHMANN, M.; PEGORARO, É. y SANMARTIN FERNANDES, C. (2013). "Steampunk e retrofuturismo: reflexos de inquietações sócio-temporais contemporâneas". Comunicação, Mídia e Consumo 10.28, 209-228.

MARGULIS, M. (2006). "Ideología, fetichismo de la mercancía y reificación". Estudios Sociológicos XXIV.70, 31-64.

MARX, K. (1971). El capital. Crítica de la Economía Política, vol. I. México: Fondo de Cultura Económica.

MATANGRANO, B. A. (2016). "O olhar contemporâneo na releitura do moderno: A lição de anatomia do temível Dr. Louison”. Estudos de Literatura Brasileira Contemporânea 48, 247-280.

MOORCOCK, M. (1971). The Warlord of Air. New York: Ace Books.

MORALES BONILLA, C. (2018). "Rastros del tiempo. Fetichismo de la mercancía, cosificación y sociedad del espectáculo". Oxímora. Revista Internacional de Ética y Política 13, 255-271.

MORENO, F. Á. (2010). Teoría de la Literatura de Ciencia Ficción. Vitoria: Portal Editions.

NEVINS, J. (2015). "Introducción: Las raíces del siglo XIX del steampunk”. En Steampunk, J. VanderMeer y A. VanderMeer (eds.), 9-16. Sevilla: Edge Entertainment.

ONION, R. (2008). "Reclaiming the Machine: An Introductory Look at Steampunk in Everyday Practice". Neo-Victorian Studies 1.1, 138163.

PALMA, F. J. (2009). El mapa del tiempo. Madrid: Alianza Editorial.

PEGORARO, É. (2012a). "Os steampunks e a cultura da mídia: apropriações de uma proposta retrofuturista no cenário brasileiro". Mediaciones Sociales 11, 83-106.

(2012b). "Steampunk: as transgressões temporais, negociadas de uma cultura retrofuturista". Cuadernos de comunicação 16.2, 389-400. (2013). "Steampunk in Brazil: Visuality and Sociability in an Urban Retro-Futuristic Culture". International Journal of Communication 
7, 1852-1863.

PÉREZ DÍAZ, P. (2018). "Una imagen fantasmagórica: modernidad, capitalismo y religión en Walter Benjamin". Revista de Humanidades de Valparaíso 6.12, 169-186.

POWERS, T. (1983). The Anubis Gates. New York: Ace Books.

PRIETO HAMES, P. (2016). "La poética del tiempo: una aproximación al imaginario steampunk". Ucoarte. Revista de Teoría e Historia del Arte 5, 95-115.

PULLMAN, P. (1995). Northern Lights. New York: Scholastic Corporation. REGIDOR NIETO, P. (2011). "El comentario de texto desde un enfoque deconstructivo". Tarbiya 41, 133-143.

SALVADOR PERIS, P. (2009). "El trayecto de la mercancía: del objeto fetiche al Yo marca". Pensar la Publicidad III.1, 139-146.

SAX, D. (2016). The Revenge of Analog. Real Things and Why They Matter. New York: PublicAffairs.

SELZNICK, B. (2007). La invención de Hugo Cabret. Madrid: Ediciones SM.

SILVA CORDEIRO, M. B., y DELÁCIO FERNANDES, C. R. (2016). "A invenção de Hugo Cabret: ilustração e cinema na literatura juvenil". Anúario de Literatura 21.2, 143-161.

STEPHENSON, N. (1995). The Diamond Age. New York: Bantam Spectra.

STERLING, B. (2009). "The user's guide to steampunk". Steampunk Magazine 5, 30-33.

THOMPSON, J. R. (2014). "Kenneth Burke Meets a Time Lord. Steampunk's Grammatical Disruption". En Clockwork Rhetoric. The Language and Style of Steampunk, B. Brummett (ed.), 115134. Jackson: University Press of Mississippi.

UDÍAS VALLINA, A. (2014). "El tiempo: una cuestión siempre abierta". Crítica 990, 24-29.

USHER, S. (2011). "The Birth of Steampunk". Letters of Note, 1 de marzo, http://www.lettersofnote.com/2011/03/birth-of-steampunk. $h$ tml [25/10/2019].

VANDERMEER, J. y CHAMBERS, S. J. (2011). Steampunk Bible. New York: Abrams Image.

VANDERMEER, J. y VANDERMEER, A. (2015). Steampunk. Sevilla: Edge Entertainment.

WOMACK, M. (2014). "Postfacio". En Retrofuturismos. Antología 
Steampunk, M. Womack (ed.), 411-419. Zaragoza: Ediciones Nevsky.

WRIGHT, J. (2014). "Steampunk and Sherlock Holmes. Performing PostMarxism". En Clockwork Rhetoric. The Language and Style of Steampunk, B. Brummett (ed.), 94-114. Jackson: University Press of Mississippi.

ZAMORA, J. A. (1999). "El concepto de fantasmagoría sobre una controversia entre W. Benjamin y Th. W. Adorno". Taula, quaderns de pensament 31-32, 129-151.

Recibido el 16 de enero de 2020.

Aceptado el 20 de abril de 2020. 